\title{
TEXT DETECTION AND EXTRACTION FROM SCENE IMAGES USING WAVELET FEATURES
}

\author{
ANGADI S.A. ${ }^{1}$, KODABAGI M.M. ${ }^{2}$, KAGAWADE V.C. ${ }^{3}$ AND VINAYAKA HITTALAMANI ${ }^{4}$ \\ 1,2,4 Department of Computer Science \& Engineering, Basaveshwar Engineering College, Bagalkot, Karnataka, India \\ ${ }^{3}$ Department of Master of Computer Applications, Basaveshwar Engineering College, Bagalkot, Karnataka, India \\ *Corresponding Author: Email- ${ }^{1}$ vinay_angadi@yahoo.com, ${ }^{2}$ malik123_mk@rediffmail.com, ${ }^{3}$ vishwanath.1312@gmail.com, \\ 4vinayakahittalamani@gmail.com
}

Received: April 12, 2012; Accepted: May 15, 2012

\begin{abstract}
Text detection and extraction from scene images is useful in finding certain facts in supporting court of laws for solving crime problems and various forensic science applications. Text detection from scene images is a difficult and challenging problem due to various issues such as; varying font size, style, uneven illumination and other degradations. In this paper, a new method that uses wavelet energy features for text detection and extraction from scene images is presented. Initially, preprocessed binarized image will be divided into $50 \times 50$ blocks. Then, wavelet energy features are obtained from every block and potential text blocks are identified using newly defined discriminant functions. Further, the detected text blocks are merged and refined to extract text regions. The proposed method is robust and achieves a detection rate of $97 \%$ on a variety of scene images each of size $240 \times 320$.
\end{abstract}

Keywords- Text detection, scene images, wavelet energy features, discriminant functions.

Citation: Angadi S.A., et al. (2012) Text detection and extraction from Scene Images using wavelet features. International Journal of Machine Intelligence, ISSN: 0975-2927 \& E-ISSN: 0975-9166, Volume 4, Issue 1, pp.-409.

Copyright: Copyright@2012 Angadi S.A., et al. This is an open-access article distributed under the terms of the Creative Commons Attribution License, which permits unrestricted use, distribution, and reproduction in any medium, provided the original author and source are credited. 